Развитие возможностей 3D оборудования стремительно вытесняет старые технологии во всех технологических областях.

3D-печать позволяет решить на производстве следующие задачи:

- ремонт и замена вышедших из строя деталей.

- $\quad$ разработка новых деталей и механизмов

- $\quad$ модернизация имеющихся систем и отдельных элементов;

Для создания полноцветных макетов используют 3D-принтеры серии ProJet x60 (ZPrinter). Они подходят для быстрой печати ярких высокоточных демонстрационных моделей.

3D-принтеры серии ProJet x60 производятся компанией 3D Systems. Они создают модели по технологии CJP из специального композитного порошка на основе гипса. Преимущества этих 3D-принтеров - высокая производительность, качество и низкая себестоимость материалов.

При изготовлении больших и сложных макетов используют фотополимерные 3D-принтеры. C их помощью изготавливают сложные части проектов, с мелкими элементами.

Список литературы:

1. Иванов В.П., Батраков А.С. Трёхмерная компьютерная графика / Под ред. Г.М. Полищука. — М.: Радио и связь, 1995. — 224 с. — ISBN 5-25601204-5

2. Снук Г. 3D-ландшафты в реальном времени на C++ и DirectX 9. - 2-еизд. М.: Кудиц-пресс, 2007. - 368 с. — ISBN 5-9579-0090-7.3. Д. Херн, М.П. Бейкер. Компьютерная графика и стандарт OpenGL. —- -е изд. — M., 2005. — 1168 c.10.

3. Маслов К.Ю., Макарова М.Ю. 3D моделирование в промышленнойсфере // Молодой ученый. - 2016. - №11.3. - С. 19-22.

4. Хомоненко А.Д., Цыганков В.М., Мальцев М.Г. Базы данных: Учебник для высших учебных заведений.

\title{
Создание программы учета автотранспорта (на примере автотранспортного цеха Нерюнгринской ГРЭС)
}

Базылев В.И., студент, Технический институт (филиал) Северо-Восточного федерального университета, 2. Нерюнгри, E-mail: vovaviper@mail.ru

Научный руководитель: к.n.н., зав. кафедрой МиИ Самохина В.М.

«Нерюнгринская ГРЭС» - тепловая электростанция (ГРЭС), расположенная в пгт. Серебряный бор Нерюнгринского района республики Саха России, входит в состав ОАО ДГК с 2005 года.

Основные направления деятельности Нерюнгринской ГРЭС - это обеспечение населения тепловой и электроэнергией. 
Но помимо основных направлений у НГРЭС есть побочные цели. У предприятия есть большой автопарк, в который входит большое количество различного транспорта. Сюда входят автобусы, автомобили для различных грузоперевозок, подъемный кран, грейдер и многое другое. И если энергетика и водоснабжение дает довольно большой доход предприятию, то автотранспорт дохода почти не приносит, работая только на предприятие.

На сегодняшний день АТЦ «НГРЭС» насчитывает 37 автомобилей различного типа: грузовые, легковые и специализированные автомобили.

Основная цель автобусного парка - перевозка сотрудников предприятия из города на рабочие места. Но при этом сотрудники проезд не оплачивают, соответственно и дохода не приносит. С остальным транспортом все еще сложнее. Крупногабаритный транспорт на ГРЭС почти не используется.

Из этих результатов на предприятии создалась тенденция сдавать транспорт в аренду. Тогда и транспорт не будет простаивать свой ресурс, и предприятие будет иметь дополнительный доход, с которого будут оплачиваться услуги водителей, закупка запчастей и топлива.

При аренде того или иного автотранспорта, создается путевка-план на срок, который будет задействован автомобиль. Отсюда появляется необходимость создания программы для автоматизации создания такой путевки.

Если взять для сравнения шаблон путевки на базе программы 1С: Бухгалтерия или Предприятие, то это безусловно удобно. Но при случайном удалении базы неопытным сотрудником, или поломке компьютера, на котором хранится шаблон, то выписка такой путевки будет затруднительной.

Однако на сегодняшний день в автотранспортном цехе путевые листы хранятся не в базе $1 \mathrm{C}$, а в программе пакета Microsoft Office - Word, что делает уязвимость этого документа еще более высокой.

Данная программа имеет следующие преимущества (слайд)

- отсутствие возможности удаления базы данных;

- удобство переноски данных, хранение будет происходить в структурном коде программы;

- программу можно хранить на носителе (флэш-карта, CD-диск, облачные хранилища, сетевые диски предприятия);

- программу не обязательно держать на компьютере, достаточно иметь копию в сетевом диске, чтобы запускать ее удаленно;

- автоматизация работы табельщицы. Нет необходимости заполнять табеля вручную, однако появится возможность выпускать готовый документ.

На данный момент программа создана на языке программирования Visual Studio $\mathrm{C}++$. Разработка велась на базе диалоговых окон с использованием библиотек MFC. По сравнению с другими языками программирования на сегодняшний день $\mathrm{C}++$ один из самых популярных и наиболее объектно-ориентированных языков программирования. A программа Microsoft Visual Studio дает большое количество возможностей для разработки в этой среде программирования.

Оболочка предполагает в себе несколько пунктов и свойств (рис.1). 


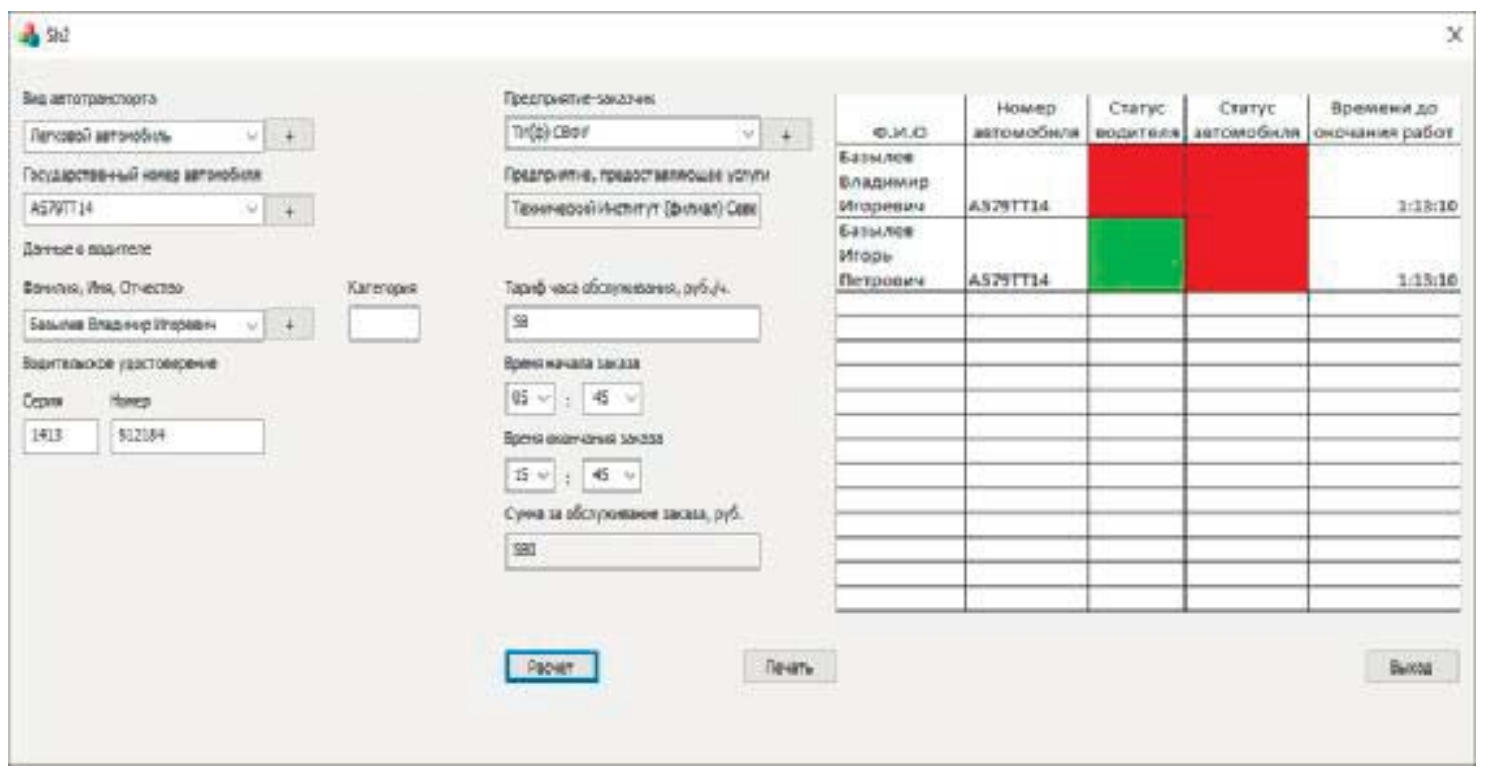

Рис. 1. Внешний вид программы учета автотранспорта

Пункты:

1. Вид транспорта (в виде выпадающего списка, данные: Автобус, Грузовой, Кран, Грейдер и др.);

2. Государственный номер (Пункт, зависящий от предыдущего);

3. Предприятие, предоставляющее услуги (Нерюнгринская ГРЭС);

4. Предприятие, которому предоставляются услуги (Первоначально крупные предприятия с которыми уже сотрудничает ГРЭС, с возможностью добавления новых предприятий вручную);

5. Данные о водителе (Фамилия, Имя, Отчество, категория, серия и номер водительского удостоверения, стаж работы и/или другие необходимые данные. Пункт связанный с 1 и 2 пунктами);

6. Дата и время начала и окончания выполнения заказа (с учетом дороги до места заказа и возвращения обратно на базу НГРЭС);

7. Тариф за час обслуживания (Формируется для каждого предприятия отдельно);

8. Предполагаемый доход, который получит транспорт за время обработки заказа (если необходимо).

Структура подключаемой базы данных отражена на рисунке 2.

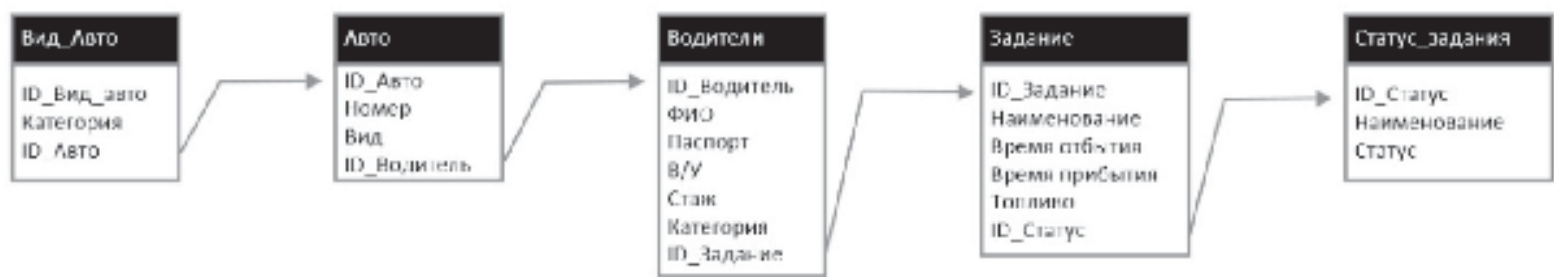

Рис. 2. Структура базы данных программы

Практическая значимость состоит в составлении табеля в формате документа MS Word и/или выводе его на печать.

Данная программа дает возможности:

- формировать путевые листы;

- рассчитывать стоимость; 
- благодаря визуализации занятости водителей быстро подбирать необходимый транспорт.

В ходе внедрения программы возможна доработка по запросу заказчика.

Список литературы:

1. http://www.dvgk.ru/ru/posts/press/nergres

2. http://museum.rao-esv.ru/power_facilities/168/

3. Официальный справочник Microsoft Visual Studio C++ [Электронный ресурс]// URL: https://msdn.microsoft.com/ru-ru/library/3bstk3k5.aspx

\title{
Разработка электронной регистратуры «Горизонт»
}

\author{
Батян А.А., студент, \\ Технический институт (филиал) \\ Северо-Восточного федерального университета, \\ 2. Нерюнгри \\ E-mail: mineski1337@gmail.com
}

Научный руководитель: к.т.н., доцент Похорукова М.Ю.

Ни для кого не секрет, что оптимизация рабочего процесса и повышение продуктивности сотрудников положительно сказывается на экономических показателях предприятия. Этих целей можно достичь различными способами, но в современных реалиях одним из самых простых и эффективных путей развития предприятия является автоматизация его инфраструктуры с использованием информационных систем. Руководствуясь этими задачами и принципами, администрация по управлению персоналом ОАО ХК «Якутуголь» приняла решение внедрить в регистратуру комплекса «Горизонт» автоматизированную информационную систему. Такая система представляет собой совокупность программных и аппаратных средств, предназначенных для управления информацией и автоматизации рутинных действий на предприятии.

Перед тем как начать проектировать и разрабатывать систему, необходимо выявить задачи, подверженные автоматизации, а также уровень и состав информационно-технической базы. В результате проведенного исследования необходимая информация была собрана. Регистратура СП «Горизонт» в рамках выполнения своих главных задач должна поддерживать следующие основные функции:

- учет сотрудников комплекса и их квалификации;

- составление графиков посещения процедур клиентами комплекса;

- подсчет стоимости препаратов и процедур;

- учет посещений клиентов;

- составление смет и отчетов для организаций, чьи сотрудники проходили лечение в оздоровительном комплексе.

С точки зрения разработчика, данные задачи можно автоматизировать с помощью внедрения в структурное подразделение информационной системы на основе СУБД и 